\title{
Environmental Factors in Etiology of Gastric Cancer
}

\author{
Showkat Ahmad Bhat ${ }^{1}$, Manzoor R. Mir ${ }^{1,}$, , Sabhiya Majid ${ }^{2}$, Muneeb U. Rehman ${ }^{1}$, Sonallah Kuchy ${ }^{3}$, \\ Bilal Ahmad Sheikh ${ }^{1}$, Ishraq Husain ${ }^{1}$, Bhudev C. Das ${ }^{4}$ \\ ${ }^{1}$ Division of Veterinary Biochemistry, Faculty of Veterinary Sciences \& Animal Husbandry (F. V. Sc \& AH), Sher-e-Kashmir University of \\ Agricultural Sciences \& Technology Kashmir (SKUAST-K), Shuhama, Alustang, Srinagar, Jammu \& Kashmir, India \\ ${ }^{2}$ Department of Biochemistry Govt. Medical College Srinagar, Srinagar, Jammu \& Kashmir, India \\ ${ }^{3}$ Department of Oncology, Govt. Medical College Srinagar, Srinagar, Jammu \& Kashmir, India \\ ${ }^{4}$ Amity Institute of Molecular Medicine \& Stem Cell Research (AIMMSCR), Amity University Uttar Pradesh Campus, Delhi, India
}

\section{Email address:}

vbcbiochemistry@gmail.com (M. R. Mir)

\section{To cite this article:}

Showkat Ahmad Bhat, Manzoor R. Mir, Sabhiya Majid, Muneeb U. Rehman, Sonallah Kuchy, Bilal Ahmad Sheikh, Ishraq Husain, Bhudev C. Das. Environmental Factors in Etiology of Gastric Cancer. Advances in Biochemistry. Vol. 3, No. 5, 2015, pp. 51-56.

doi: 10.11648/j.ab.20150305.11

\begin{abstract}
Among all the cancers Gastric cancer has been reported to be a highly prevalent malignancy In Kashmir valley, constitutes about $30 \%-40 \%$ of all malignancies. Cancer is consistently considered as significant environmental issue besides other etiological factors. In our study the incidence ratio among genders remained 3:1(male to female). More incidents were found in 60-64 years of age, $34.5 \%$ patients reported weight loss and the weight difference was about $10 \mathrm{~kg}$ from stage I to Stage $\mathrm{IV}, 62 \%$ of the patients were illiterate, $59.5 \%$ of patients were from poor and middle class and $51 \%$ patients had faced the Water pollution. Major portion $53 \%$ of patients belongs to farmers\& house wives among these 38.6\%, 12.2\%, 8.4\%, 21.6\% \& 18.8\% had exposure to Pesticides/insecticides, Fungicides, Chemicals, Fertilizer, Manure respectively. At the time of diagnosis patients presented with multiple symptoms like dyspepsia $76.5 \%$, loss of appetite $35.5 \%$ and vomiting $42.0 \%$. On physical examination, anaemia was the most common sign and was present in $16381.5 \%$, ascites was $11.1 \%$, epigastric mass in $9.9 \%$ Regarding distribution of cancer within the stomach, distal stomach was involved in 45.5\%, proximal stomach in $42.0 \%$ of patients; Middle stomach and Whole stomach were involved in $6.0 \%$ each. Among the common symptom, ulceroproliferative type was seen in $35.5 \%$, ulcerative lesions were $30 \%$ and infiltrative were in $7.0 \%$.Various perceptible effects during our study provides significant evidence to conclude that in gastric cancer etiology, environment plays an important role.
\end{abstract}

Keywords: Gastric Cancer, Environmental Pollution, Occupation, Farming, Socio-demographic Profile, Clinical Presentation

\section{Introduction}

Gastric cancer (GC) continues to be the second most frequent malignant neoplasm around the globe with varied regional incidences due to different environmental factors. Kashmir has high incidences of cancers and GC constitutes about 30\%-40\% of all malignancies reported in Kashmir (Prakash et al, 2005). In developed countries, especially in Japan, despite having GC epidemic in the past a decline in GC as a result of mass screening has been reported since 1970 (Nawroz et al, 1996). Till date GC has remained a major clinical challenge due to its poor prognosis, limited treatment options, relatively resistance to chemotherapy / radiotherapy and late diagnosis of the disease. Environmental pollution may be described as the man-made unfavorable alteration of our surroundings that takes place through changes in energy patterns, radiation levels, chemical, physical and biological alterations. Pollution includes the release of materials into the atmosphere which make the air unsuitable for inhalation, damage the quality of soil or water and release substances which damage the health of human beings, plants and animals. The impact of the environment on the human body evidently are the systems that are exposed to hazardous materials such as covering the external skin, the internal respiratory and alimentary systems and with an ultimate bearing on the structures and organs of the body as a whole. While many ailments like asthma and allergies are known to be environment linked, cancer is consistently considered as significant environmental issue besides other etiological factors. (Raj et al, 2003).

It has been observed that the cause and development of 
nearly every human disease is in some way related to environmental factors. Physical factors, infectious agents, toxic chemicals and physiological stress, all participate a role in the beginning or improvement of different human diseases. The chance that an individual will develop cancer in response to a particular environmental agent depends on several interacting factors i.e. how long and how often a person is exposed to a particular substance, his/her exposure to lifestyle, diet, genetic factors, health, age, and gender. Diet, alcohol consumption and certain medications can affect the levels of chemicals in the body that break down into cancer-causing substances. Because of the complex interplay of many factors, it is still not possible to predict whether a specific environmental exposure will cause a particular person to develop cancer or not. (Hagmaret al, 1992). We know that certain genetic and environmental factors increase the risk of developing cancer, but we rarely know exactly which combination of factors are responsible for a person's specific cancer. This also means that we usually don't know why one person gets cancer and another does not.

Globally, the highest rate in males was seen in Japan-80/100,000 and the lowest rate was in Thailand, around $3 / 100,000$ population. All others are in the National network of registries under the Indian Council of Medical Research. As reported by the population-based cancer registries in India 2006-2008, stomach cancer is one among the 5 leading cancers in and among females it is the third most common cancer. In the National Cancer Registry Programme, the incidence rate and distribution of stomach cancer in Kashmir are not available due to lack of both population and hospital based cancer registries. In 1990, analyzing the histologically proved cancer cases seen during 1983-1987 in the Pathology Department of Sheri Kashmir Institute of Medical Sciences, Srinagar, it was reported that stomach cancer formed $31 \%$ of all cancer in men and 18\% in women (Azra et al, 1990). The only population based study from Kashmir analyzing data obtained during 1986-89 observed that the age adjusted stomach cancer incidence among males was 36.7 and among females it was 9.9/100,000 (Khuroo et al, 1992), indicating that there is a high rate of gastric cancer in Kashmiri population compared to other parts of the country. Different dietary practices, environmental pollution, different occupation and peculiar life style habits of the natives has been implicated for such variation. Such remarkable differences called for special studies.

Consistent positive findings were found for the occupations of firefighters, fishermen, carpenters, plasterers, miners, sailors, cooks and restaurant personnel. Excess risks were also seen in the farmers, meat industry, the rubber industry and the leather footwear industry. (Chow et al, 1994). Majority of risk estimates among farm related occupations are greater, which suggests possible occupational etiologies (Coggon et al, 1889).Farmers have shown elevated risks of stomach cancer in the majority of studies (Pierluigi et al, 2001). These excess risks have been seen with different study designs in different time periods and in various countries (Blair et al, 1991), (Blair et al, 1993), (Delzell et al, 1985). Workplace exposures in farming that may be of etiologic importance for gastric cancer includes organic and inorganic dusts, pesticides, fertilizers, and diesel fuel (Blair et al, 1991). Of these exposures, pesticides and fertilizers have been evaluated mainly in relation to gastric cancer risk (Fincham et al, 1992). Acute need is felt to understand the role of environment, genetic predispositions and the occupational exposures to pollutants as possible etiology for gastric cancer. Thist ype of study is the first study in Kashmir valley.

\section{Materials and Methods}

A descriptive study of stomach cancer was conducted over a period of December 2013 to February 2015 jointly by the Division of Vety. Biochemistry of F.V.Sc \& AH, SKUAST-K, Department of Biochemistry of Government Medical College, (GMC) Srinagar \& Department of Oncology of Government Medical College, Srinagar. Two hundred patients with histologically diagnosed stomach cancer were interviewed using a pre-tested semi-structured questionnaire and relevant demographic and environmental data were recorded, as regarding symptoms, family history, Occupation and Environment pollution around.

\section{Results}

\subsection{Age, Stage, Weight \& Height Distribution in Gastric Cancer Patients}

During the study period there were 200 patients (males 150 female - 50), male to female ratio, Age, stage, weight \& height distribution of Gastric Cancer Cases is given in table I. The male to female ration was $3: 1$, as male showed higher incidences of gastric cancer in valley. More incidents were found in age of 60-64. There was found decrease in weight in cancer patients as per the stage is concerned, the average weight was as $66 \mathrm{~kg}, 64 \mathrm{~kg}, 58 \mathrm{~kg}, 56 \mathrm{~kg}$ in Stage I, Stage II, Stage III, Stage IV respectively.

Table I. Age, stage, weight \& height distribution in patients.

\begin{tabular}{|c|c|c|c|c|}
\hline Age & Male (M) & \multicolumn{2}{|c|}{ Female (F) } & \\
\hline $20-24$ & 2 & \multicolumn{2}{|c|}{0} & \\
\hline $25-29$ & 4 & \multicolumn{2}{|l|}{0} & \\
\hline $30-34$ & 0 & \multicolumn{2}{|l|}{0} & \\
\hline $35-39$ & 0 & \multicolumn{2}{|l|}{0} & \\
\hline $40-44$ & 2 & \multicolumn{2}{|l|}{2} & \\
\hline $45-49$ & 8 & \multicolumn{2}{|l|}{8} & \\
\hline $50-54$ & 28 & \multicolumn{2}{|l|}{2} & \\
\hline $55-59$ & 8 & \multicolumn{2}{|l|}{4} & \\
\hline $60-64$ & 40 & \multicolumn{2}{|l|}{10} & \\
\hline $65-69$ & 24 & \multicolumn{2}{|l|}{8} & \\
\hline $70-74$ & 30 & \multicolumn{2}{|l|}{14} & \\
\hline $75+$ & 4 & \multicolumn{2}{|l|}{2} & \\
\hline Total & 150 & \multicolumn{2}{|l|}{50} & \\
\hline STAGES & \multicolumn{2}{|c|}{ Number of Cases in each stage } & $\begin{array}{l}\text { Average } \\
\text { weight }\end{array}$ & $\begin{array}{l}\text { Average } \\
\text { height }\end{array}$ \\
\hline Stage I & 40 & & $66 \mathrm{~kg}$ & $5^{\prime} .7^{\prime \prime}$ \\
\hline Stage II & 50 & & $64 \mathrm{~kg}$ & $5^{\prime} .5^{\prime \prime}$ \\
\hline Stage III & 60 & & $58 \mathrm{~kg}$ & 5'.6" \\
\hline Stage IV & 50 & & $56 \mathrm{~kg}$ & $5^{\prime} .7^{\prime \prime}$ \\
\hline
\end{tabular}




\subsection{Socio-demographic Profile of Stomach}

The socio-demographic profiles of patients are shown in Table II. Social class scale is based on education of head of family, per capita monthly income and occupation. $62 \%$ of the patients were illiterate. Almost $59.5 \%$ of patients were from poor and middle class. In occupation fields farmers are involved more it is about $42.5 \%$,of all the occupations. House wives involved about $10.5 \%$ in all occupations.

Table II. Socio-demographic Profile of Stomach.

\begin{tabular}{|c|c|c|c|c|c|}
\hline Cancer Patients & & & & No. & Percentage \\
\hline \multirow{2}{*}{ Sex } & \multicolumn{3}{|l|}{ Male } & 150 & $75.0 \%$ \\
\hline & \multicolumn{3}{|l|}{ Female } & 50 & $25.0 \%$ \\
\hline \multirow{2}{*}{ Residence } & \multicolumn{3}{|l|}{ Urban } & 29 & $14.5 \%$ \\
\hline & \multicolumn{3}{|l|}{ Rural } & 71 & $35.5 \%$ \\
\hline \multirow{5}{*}{ Education } & \multicolumn{3}{|l|}{ Illiterate } & 124 & $62.0 \%$ \\
\hline & \multicolumn{3}{|l|}{ Primary } & 12 & $6.0 \%$ \\
\hline & \multicolumn{3}{|l|}{ Middle } & 24 & $12.0 \%$ \\
\hline & \multicolumn{3}{|l|}{ Higher Secondary } & 28 & $14.0 \%$ \\
\hline & \multicolumn{3}{|l|}{ Higher education } & 12 & $6.0 \%$ \\
\hline \multirow{20}{*}{ Occupation } & \multirow{2}{*}{ House-wife } & $\mathrm{M}$ & $\mathrm{F}$ & $\mathrm{T}$ & Percentage \\
\hline & & 0 & 21 & 21 & $10.5 \%$ \\
\hline & $\begin{array}{l}\text { Government } \\
\text { employee }\end{array}$ & 12 & 5 & 17 & $8.5 \%$ \\
\hline & Farmer & 71 & 14 & 85 & $42.5 \%$ \\
\hline & Butcher & 3 & 2 & 5 & $2.5 \%$ \\
\hline & Foot wear (Cob) & 4 & 0 & 4 & $2.0 \%$ \\
\hline & Cook & 6 & 0 & 6 & $3.0 \%$ \\
\hline & Rice mill & 4 & 0 & 4 & $2.0 \%$ \\
\hline & Floor & 3 & 1 & 4 & $2.0 \%$ \\
\hline & Band saw & 5 & 0 & 5 & $2.5 \%$ \\
\hline & Stone crusher & 5 & 0 & 5 & $2.5 \%$ \\
\hline & Brick Kiln & 5 & 0 & 5 & $2.5 \%$ \\
\hline & Mechanic & 8 & 0 & 8 & $4.0 \%$ \\
\hline & Plasterer & 5 & 0 & 5 & $2.5 \%$ \\
\hline & Sailor & 2 & 2 & 4 & $2.0 \%$ \\
\hline & Firefighter & 3 & 0 & 3 & $1.5 \%$ \\
\hline & Baker & 2 & 1 & 3 & $1.5 \%$ \\
\hline & Metal molder & 5 & 0 & 5 & $2.5 \%$ \\
\hline & Carpenter & 4 & 0 & 4 & $2.0 \%$ \\
\hline & $\begin{array}{l}\text { Fishermen / } \\
\text { Fisherwomen }\end{array}$ & 3 & 4 & 7 & $3.5 \%$ \\
\hline & Upper High & & & 9 & $4.5 \%$ \\
\hline & High & & & 34 & $17.0 \%$ \\
\hline Socioeconomic & Upper Middle & & & 38 & $19.0 \%$ \\
\hline & Lower Middle & & & 61 & $30.5 \%$ \\
\hline & Poor & & & 58 & $29.0 \%$ \\
\hline
\end{tabular}

\subsection{Type of Pollution Faced by Patients in Surroundings}

Among 94 patients faced the different type of pollutions $22.3 \%, 26.5 \%, 51.0 \%$ had faced the Soil pollution, air pollution \& water pollution respectively and in among 106 cases of Farmers \& house wives, 38.6\% ( 1 to 2 times within 2 months), $12.2 \%$ ( 1 to 2 times within 2 months), 8.4 ( 1 to 2 times within 3 months), 21.6 ( 1 to 2 times within 15 days) \& 18.8 (Almost every day)had exposure to Pesticides/insecticides, Fungicides, Chemicals, Fertilizer, Manure respectively.
Table III. Pollution faced by patients in surroundings.

\begin{tabular}{|c|c|c|c|c|}
\hline Pollution & $\mathbf{M}$ & $\mathbf{F}$ & Total & $\%$ age \\
\hline Soil pollution & 14 & 7 & 21 & 22.3 \\
\hline Air pollution & 16 & 9 & 25 & 26.5 \\
\hline Water pollution & 25 & 23 & 48 & 51.0 \\
\hline Total & 55 & 39 & 94 & \\
\hline \multicolumn{4}{|c|}{$\begin{array}{l}\text { No. of Farmers \& house wives exposed (How long exposed \& } \\
\text { how often) } 106\end{array}$} & $\%$ age \\
\hline Pesticides/insecticides & 34 & 7 & 41 & 38.6 \\
\hline Fungicides & 20 & 2 & 13 & 12.2 \\
\hline Other chemicals & 10 & 0 & 9 & 8.4 \\
\hline Fertilizer & 19 & 5 & 23 & 21.6 \\
\hline Manure & 14 & 12 & 20 & \multirow{2}{*}{18.8} \\
\hline Total & 85 & 21 & 106 & \\
\hline Average exposure & & \multicolumn{3}{|c|}{$\begin{array}{l}\text { No. of cases in each } \\
\text { category }\end{array}$} \\
\hline Pesticides/insecticides & $\begin{array}{l}1 \text { to } 2 \text { times within } \\
2 \text { months }\end{array}$ & \multicolumn{3}{|l|}{41} \\
\hline Fungicides & $\begin{array}{l}1 \text { to } 2 \text { times within } \\
2 \text { months }\end{array}$ & \multicolumn{3}{|l|}{13} \\
\hline Other chemicals & $\begin{array}{l}1 \text { to } 2 \text { times within } \\
3 \text { months }\end{array}$ & \multicolumn{3}{|l|}{9} \\
\hline Fertilizer & $\begin{array}{l}1 \text { to } 2 \text { times within } \\
15 \text { days }\end{array}$ & \multicolumn{3}{|l|}{23} \\
\hline Manure & Almost every day & \multicolumn{3}{|l|}{20} \\
\hline
\end{tabular}

\subsection{Clinical Presentation of Gastric Cancer Cases}

The clinical presentation, site and type of lesion of stomach cancer patients are shown in Table IV. Weight lossis a very common sign for stomach cancers. In the current series, 69 patients $(34.5 \%)$ reported weight loss. At the time of diagnosis patients presented with multiple symptoms like dyspepsia (76.5\%), loss of appetite $35.5 \%$ and vomiting $42.0 \%$. On physical examination, anaemia was the most common sign and was present in $163(81.5 \%)$, ascites was present in 9 patients $(11.1 \%)$, epigastric mass in $8(9.9 \%)$ and one patient had spleenomegaly . Regarding distribution of cancer within the stomach, distal stomach was involved in $45.5 \%$, proximal stomach in $42.0 \%$ of patients; middle stomach and whole stomach were involved in $6.0 \%$ each. Among the common symptom, ulceroproliferative type was seen in $35.5 \%$, ulcerative lesions were $30 \%$ and infiltrative were in $7.0 \%$.

Table IV. Clinical Presentation of patients.

\begin{tabular}{llll}
\hline Clinical Presentation & $\begin{array}{l}\text { No. of Patients } \\
(\mathbf{n = 2 0 0 )}\end{array}$ & \% (n=200) \\
\hline \multirow{5}{*}{ Symptoms } & Dyspepsia & 153 & 76.5 \\
& Anemia & 163 & 81.5 \\
& GI Bleed & 83 & 41.9 \\
& Weight Loss & 69 & 34.5 \\
& Vomiting & 71 & 35.5 \\
& Loss of appetite & 84 & 42.0 \\
Site of Lesion & Proximal Stomach & 84 & 42.0 \\
& Distal Stomach & 91 & 45.5 \\
& Mid Stomach & 12 & 6.0 \\
& Diffuse & 13 & 6.0 \\
& Ulceroproliferative & 71 & 35.5 \\
Type of Lesion & Proliferative & 51 & 25.5 \\
& Ulcerative & 60 & 30.0 \\
& Infiltrative & 14 & 7.0 \\
\hline
\end{tabular}




\subsection{Histopathology of Gastric Patients}

The microscopic verification diagnosis of histopathology is given in Table V. Histopathologically nearly half of lesions were well differentiated adenocarcinoma.

Table V. Histopathology of patients.

\begin{tabular}{lllll}
\hline Adenocarcinoma & M & F & Total & \% \\
\hline Well Differentiated & 70 & 24 & 94 & 47 \\
Moderately Differentiated & 19 & 7 & 26 & 13 \\
Poorly Differentiated & 57 & 19 & 76 & 38 \\
Mixed & 0 & 4 & 4 & 2 \\
Total & 146 & 54 & 200 & \\
\hline
\end{tabular}

\section{Discussion}

Gastric cancer has a wide geographic variation among countries in Asia with a high incidence include Japan, China and South Korea and those with a low incidence include India, Pakistan and Thailand. (Sinha et al, 2003) has reiterated that India is country in transition from "developing" to a "developed" nation where dietary customs and habits are diverse and are linked to religion and social values. In India, across the various cancer registries, there is a wide variation in the prevalence of gastric carcinoma with incidence rates five times higher in South India than North India (Kwong et, a.2008). Besides south Indian states, Kashmir in the North India too has the highest incidence $(65.25 \%)$ of gastric carcinoma. In India most of the studies on gastric carcinoma are based on diet and clinical reports. There is paucity of information on environmental based studies with respect to prevalence and control of gastric cancer. However, whether environment has any influence on the risk of gastric cancer in Kashmiri population is yet to be determined.

Globally variations observed in gastric cancer incidence in populations have provided leads to study the factors associated with stomach cancer. Kashmir, one of the three provinces of Jammu \& Kashmir state is in the northern most part of the country and the beautiful hilly terrain, gifted natural settings and the peculiar life style, environment \& occupation of the people are significant. Almost 95\% are Muslims, 4\% Hindus and the rest follow Sikh religion. Earlier reported studies indicated a high prevalence of stomach and esophageal cancer. The reported incidence data highlighted the incidence with a high male to female ratio among stomach cancer patients, In the present study the sex distribution of gastric carcinoma, the male and female ratio reveals $3: 1$, so males are predominantly susceptible to gastric carcinoma and this is consistent with the results of other studies (Mariya Ami et. al, 2003), (Phukan et. a, 2005) and (Bulent et. al, 2006). Consistent positive findings were found for the occupations of House-wife, Government employee, Farmer, Butcher, Foot wear (Cob), Cook, Rice mill, Floor, Band saw, Stone crusher, Brick Kiln, Mechanic, Plasterer, Sailor, Firefighter, Baker, Metal molder, Carpenter, Fishermen/Fisherwomen. For a few occupations, such as cook, restaurant personnel, and workers in the meat industry, diet may play a strong role (Raj et al, 2003), (Pierluigi et al, 1999) (Blair et al, 1991).Our study showed overall there was highest risk of gastric cancer among farmers which supports the findings of Blair et al 1991 and Blair et al 1993 and suggests possible occupational etiologies. These excess risks have been seen with different study designs in different time periods and in various countries (Delzell et al, 1985), (Blair et al, 1991), (Fincham et al, 1992) and (Sinha et al, 2003). Workplace exposures in farming that may be of etiologic importance for gastric cancer includes organic and inorganic dusts, pesticides and fertilizers. Our results have showed that in Farmers \& house wives, 38.6\% (1 to 2 times within 2 months), $12.2 \%$ ( 1 to 2 times within 2 months), 8.4 (1 to 2 times within 3 months), 21.6 ( 1 to 2 times within 15 days) \& 18.8 (Almost every day) had exposure to Pesticides/insecticides, Fungicides, Chemicals, Fertilizer, Manure respectively. Among these exposures, pesticides and fertilizers have been evaluated mainly in relation to gastric cancer risk which supports the findings of (Koutros et al, 2010), (Koutros et al, 2009).

Alarming symptoms accompanying dyspeptic symptoms do not only have a diagnostic role in signifying the probable presence of gastric cancer, but when referred to diagnosis. It may suggest the site, stage and aggressiveness of cancer and usually indicate poor prognosis. In our study we evaluated the association of alarming symptoms, such as dysphagia, weight loss, and vomiting with pathology and site of cancer and stage. Alarming symptoms among patients were presenting on comparable to those with uncomplicated dyspepsia as far as concerns age, sex and pathology of gastric cancer, but more frequently showed a distal stomach site, which was supported by other workers (Maconi et al, 2003 ).These all symptoms should alert the healthcare providers about the possibility of gastric cancer. Stephens showed that the figure of alarming symptoms, at presentation, correlated with the stage of the tumor, in that patients with the greatest number of alarm symptoms presented with the most advanced disease (Stephens et al, 2005) and Bowrey, study showed that approximately $50 \%$ of the patients with alarm symptoms had stage IV disease (Bowrey et a,1 2006 ). Indeed, the relationship between symptoms and stage of cancer is conceivable if we consider the profile of symptoms in early gastric cancer which are not unlike those of benign gastric ulcer rather than advanced cancer. Epigastric pain and dyspepsia are very frequently present, whilst alarm symptoms occur in only a minority of patients. $7.6 \%$ patients in our study had a positive family history which was similar to another study (Everett et al, 1997). However, many other studies have reported a positive family history of $17 \%$ of patients (Safaee et al, 2009). Our low estimate of family history could have been because of poor reporting by patient attendees. The most common presenting symptoms in our study abdominal pain (61.4\%) and weight loss (59.5\%), which were similar to other studies (Safaee et al, 2009) and (Medina et al, 2000). Our findings revealed that most common site of tumor was distal stomach $(45.5 \%)$ followed by proximal stomach $(42 \%)$ which are consistent with other studies (Eskandar et al, 2006,(Plummer et al, 2005) and (Inoue et al, 2005). Our results of histopathology of gastric 
cancer patients showed $47 \%$ were well differentiated, $13 \%$ were moderately differentiated, $38 \%$ were poorly differentiated and rest $2 \%$ were mixed, which supports the work of other workers who showed in their study that during histopathology examination most of biopsies of the tissue of gastric cancer patients showed well differentiated results (Kim et al, 2003). This highlights the need for aggressive biopsy for minimally symptomatic patients to improve the survival.

\section{Conclusion}

Gastric cancer is one of the most common malignancies worldwide and despite its declining incidence in developed countries; it remains an important public health burden that is likely due to sustenance by environmental risk factors, both known and unknown. Wide range of perceptible effects provides substantial evidence to conclude that the environment may have a role in gastric cancer and it is important to increase the awareness among general population regarding the etiology and hazardous materials in environment which may be causative agents for gastric cancer and active participation of health providers in this regard is required for prevention and early detection.

\section{Acknowledgments}

Authors would like to thank the Indian Council of Medical Research (ICMR),V. Ramalingaswami Bhawan Ansari Nagar, Post Box - 4911, New Delhi - 110 029) for their support vide Research grant as senior research fellowship to the first author.

\section{Author's Contribution}

All the authors have contributed equally. All authors read and approved the final manuscript.

\section{References}

[1] Azra, Jan, GM. (1990). Pattern of cancer at Srinagar (Kashmir). Indian J Pathol Microbiol, 33, 118-23.

[2] Blair, A., Dosemeci, M., Heineman, EF. (1993) Cancer and other causes of death among male and female farmers from twenty-three states. Am J Ind Med 23:729-42.

[3] Blair, A., Zahm, SH. (1991) Cancer among farmers. Occup Med; 6:335-54.

[4] Bowrey, DJ., Griffin, SM., Wayman, J., Karat, D., Hayes, N., Raimes, SA. (2006) Use of alarm symptoms to select dyspeptics for endoscopy causes patients with curable esophagogastric cancer to be overlooked. SurgEndosc; 20: 1725-1728.

[5] Bulent, Y., Nurullah, Z., Fazli, A. (2006) The clinical and pathological features of patients with gastric cancer in Turkey: A Turkish Oncology Group Study. Turkish Journal of Cancer, 36,3 .

[6] Chow, WH., McLaughlin, JK., Malker, HSR.(1994)
Occupation and stomach cancer cohort of Swedish men. Am J Ind Med; 26:511-20.

[7] Coggon, D., Pannett, B., Pippard, EC. (1989) Lung cancer in the meat industry. Br J Ind Med; 46:188-91.

[8] Delzell, E., Grufferman, S. (1985) Mortality among white and nonwhite farmers in North Carolina, 1976-1978. Am J Epidemiol; 121:391 402.

[9] Eskandar. H., Hossein, SS., Rahim, M. (2006) Clinical profile of gastric cancer in Khuzestan, southwest of Iran. World J Gastroenterol; 12:48325.

[10] Everett, SM., Axon, AT. (1997) Early gastric cancer in Europe. Gut; 41: 142-150.

[11] Fincham, SM., Hanson, J., Berkel, J. (1992) Patterns and risks of cancer in farmers in Alberta. Cancer; 69:1276-85.

[12] Hagmar, L., Linden, K., Nilsson, A. (1992) Cancer incidence and mortality among Swedish Baltic Sea fishermen. Scand J Work Environ Health; 18:217-24.

[13] Inoue, M., Tsugane, S. (2005) Epidemiology of gastric cancer in Japan. Postgrad Med J ;81:41924.

[14] Khuroo, MS., Zargar, ZA., Mahajan, R. (1992) High incidence of esophageal and gastric cancer in Kashmir - in a population with special personal and dietary habit. Gut, 33, 11-5.

[15] Kim, DY., Ryu, SY., Kim, YJ. (2003) Clinicopathological characteristics of gastric carcinoma in young patients. Langenbecks Arch Surg; 388.

[16] Koutros, S., Alavanja, MC., Lubin, JH. (2010) An update of cancer incidence in the Agricultural Health Study. Journal of Occupational and Environmental Medicine; 52(11):1098-1105.

[17] Koutros, S., Lynch, CF., Ma, X. (2009) Heterocyclic aromatic amine pesticide use and human cancer risk: results from the U.S. Agricultural Health Study. International Journal of Cancer; 24(5):1206-1212.

[18] Kwong, MF., Nick T., Paul M., Richard H., Takeshi A., Kentaro, S. (2008) Asia-Pacific Consensus Guidelines on Gastric Cancer Prevention. J Gastroenterol Hepatol.; 23(3):351-365.

[19] Maconi, G., Kurihara, H., Panizzo, V., Russo, A., Cristaldi, M., Marrelli, D., Roviello, F. (2003) Gastric cancer in young patients with no alarm symptoms: focus on delay in diagnosis, stage of neoplasm and survival. Scand J Gastroenterol; 38: 1249-1255.

[20] Mariya, AQ., Muneer, AH., Showkat AH. (2006) Gastric Cancer in Kashmir. Asian Pacific J Cancer Prev, 12, 303-307.

[21] MedinaFranco, H., Heslin, MJ., CortesGonzalez, R. (2000) Clinicopathological characteristics of gastric carcinoma in young and elderly patients: a comparative study. Ann Surg Oncol; 7:5159.

[22] Nawroz, H., Koch, W., Anker, P., Stroun, M., Sidransky, D. (1996) Microsatellite alterations in serum DNA of head and neck cancer patients. Nat Med. 2:9:1035-7.

[23] Phukan, RK., Zomawia, E., Narain, K. (2005). Tobacco use and stomach cancer in Mizoram, India. Cancer Epidemiol Biomarkers Prev, 14, 1892-6. 
[24] PierluigiCocco, Mary, H., Ward. Occupational Risk Factors for Gastric Cancer. Epidemiologic Reviews by the Johns Hopkins University School of Hygiene and Public Health, Vol. 18, No. 2 .

[25] Plummer, JM., Gibson, TN., McFarlane, ME. (2005) Clinicopathologic profile of gastric carcinomas at the University Hospital of the West Indies. West Indian Med J; $54: 3648$.

[26] Prakash, S., Sarran, L., Socci, N., DeMatteo, RP., Eisenstat, J., Greco, AM., Maki, RG., Wexler, LH. (2005) gastrointestinal stromal tumors in children and young adults: a clinicopathologic, molecular, and genomic study of 15 cases and review of the literature. Journal Pediatric Hematol Oncol. 27:4:179-87.
[27] Raj, A., Mayberry, JF., Podas, T. (2003) occupation and gastric cancer. Postgrad Med J ; 79:252-258

[28] Safaee, A., Moghimi, DB., Fatemi, SR. (2009) Clinicopathological Features of Gastric Cancer: A Study Based on Cancer Registry Data. IJCP ;2:6770.

[29] Sambasivaiah, K., Ibrarullah, M., Reddy, MK. (2004) Clinical profile of carcinoma stomach at a tertiary care hospital in south India. Trop Gastroenterol; 25:216.

[30] Sinha, R., Anderson, DE., McDonald, SS., Greenwald, P. (2003) Cancer risk and diet in India. J postgrad Med; 49; 222-228.

[31] Stephens, MR., Lewis, WG., White, S., Blackshaw, GR., Edwards, P., Barry, JD., Allison, C. (2005) Prognostic significance of alarm symptoms in patients with gastric cancer. Br J Surg; 92: 840-846. 